Article

\title{
Insight into the Role and Mechanism of Nano MgO on the Hot Compressive Deformation Behavior of Mg-Zn-Ca Alloys
}

\author{
Haoran Zheng ${ }^{1}$, LeiTing Yu ${ }^{1}$, Shaoyuan Lyu ${ }^{1}$, Chen You ${ }^{1}$ and Minfang Chen ${ }^{1,2, *}$ \\ 1 School of Materials Science and Engineering, Tianjin University of Technology, Tianjin 300384, China; \\ zhenghaoran916@163.com (H.Z.); 18730607235@163.com (L.Y.); bklvshaoyuan@126.com (S.L.); \\ youchentj@126.com (C.Y.) \\ 2 Key Laboratory of Display Materials and Photoelectric Device (Ministry of Education), Tianjin 300384, China \\ * Correspondence: mfchentj@tjut.edu.cn; Tel.: +86-022-6021-6916
}

Received: 7 September 2020; Accepted: 8 October 2020; Published: 12 October 2020

\begin{abstract}
Aiming to investigate the role and mechanism of nano $\mathrm{MgO}$ on the hot compressive deformation behavior of Mg alloys, the Mg-3Zn-0.2Ca alloy (MZC, in $\mathrm{wt}^{\circ} \%$ ) and the $0.2 \mathrm{MgO} / \mathrm{Mg}-$ $3 \mathrm{Zn}-0.2 \mathrm{Ca}$ alloy (MZCM, in $\mathrm{wt} \%$ ) were investigated systematically in the temperature range of $523-673 \mathrm{~K}$ and the strain rate range of $0.001-1 \mathrm{~s}^{-1}$. MZCM shows finer grains and second phase because of the refinement effects of added $\mathrm{MgO}$. Flow behavior analysis shows that the addition of nano $\mathrm{MgO}$ promotes the dynamic recrystallization (DRX) of MZC. The flow stress of MZCM is lower than that of MZC during deformation at 523-623 K but exhibits a reverse trend at $673 \mathrm{~K}$ and $0.1-1 \mathrm{~s}^{-1}$. The constitutive analysis indicates that dislocation climb is the dominant deformation mechanism for MZC and MZCM. The addition of nano $\mathrm{MgO}$ particles decreases the stress sensitivity and deformation resistance for thermal deformation and improves the plasticity of the MZC. Besides, according to the processing map constructed at strains of 0.7 and corresponding microstructure evolution, MZCM exhibits higher power dissipation efficiency and smaller instability regions than MZC, and the optimum hot working condition for MZCM was determined to be at $623-653 \mathrm{~K}$ and $0.01-0.001 \mathrm{~s}^{-1}$.
\end{abstract}

Keywords: $\mathrm{MgO} / \mathrm{Mg}-\mathrm{Zn}-\mathrm{Ca}$ composite; hot deformation; processing map; dynamic recrystallization

\section{Introduction}

Research on magnesium $(\mathrm{Mg})$ and its alloys as biodegradable implants has grown for years due to their biodegradability, biocompatibility and moderate mechanical properties close to those of bone [1]. Aiming to further improve the bioactivity and mechanical properties of $\mathrm{Mg}$ alloys [2], Mg-matrix composites (MMCs) have been studied in the last decade. These materials use micro or nano-sized ceramic particles as reinforcements, such as calcium phosphate particles (CPP) [3], hydroxyapatite (HA) [4], tricalcium phosphate ( $\beta$ - TCP) [5], $\mathrm{ZrO}_{2}$ [6], $\mathrm{Al}_{2} \mathrm{O}_{3}$ [7], $\mathrm{ZnO}$ [8] and $\mathrm{TiB}_{2}$ [9], which improve the yield strength (YS) and utimate tensile strength (UTS) of Mg alloys. However, these enforcement particles have disadvantages of serious aggregation and nonuniform distribution, and a poor interface between the particles and magnesium matrix, leading to the deterioration in mechanical properties. Additionally, the aforementioned ceramic particles are stable in the inner physiological environment, which forms nondegradable residues in vivo when used as enforcement in MMC implants.

Due to their small intrinsic flaws and good $\mathrm{MgO} / \mathrm{Mg}$ interfacial bonding [10], $\mathrm{MgO}$ nanoparticles became one of the most promising reinforcement for MMCs. Our previous research [11] shows that the orientation relationships of $(111) \mathrm{MgO} \sim 2.62^{\circ}$ from $(0002) \alpha-\mathrm{Mg}$ and $[0-11] \mathrm{MgO} / /[2-1-10] \alpha-\mathrm{Mg}$ were observed at the interface of $\mathrm{Mg} / \mathrm{MgO}$, which verified the excellent interfacial bonding, resulting in 
a compatible deformation in MMCs. Thus, the mechanical properties of MgO-added MMCs are dramatically enhanced. Furthermore, the addition of $\mathrm{MgO}$ forms a dense protective film to achieve uniform corrosion of the composites, which benefits to improve the corrosion resistance of MMCs to meet the corresponding benchmark of biodegradable implants (corrosion rate $<0.5 \mathrm{~mm} / \mathrm{y}$ ) [12]. Moreover, as a homologous substance to the $\mathrm{Mg}$ matrix, $\mathrm{MgO}$ can transfer to water-soluble $\mathrm{MgCl}_{2}$ completely in a chloridion-rich physiological environment, which avoids the formation of nondegradable residues.

Importantly, as MMCs have poor workability at room temperature due to the aggregation of ceramic particles, hot working is an effective method to refine grains and break up ceramic particles in MMCs [13], which enhances the plasticity of them dramatically. Xiao et al. [14] studied the hot deformation behavior of in-situ nano-sized $\mathrm{TiB}_{2} / \mathrm{AZ} 91$ composite by analyzing the constitutive equation, hot processing maps and microstructure evolution, revealing that the in-situ nano-sized $\mathrm{TiB}_{2}$ particles increase the deformation resistance of AZ91 during thermal deformation. Therefore, an effective way to investigate the hot deformation behavior and identify the optimum hot processing parameters is by developing hot processing maps $[15,16]$ and constitutive equations [17]. However, the current corresponding research on MMCs is not systematic enough, and no research has investigated the effect of $\mathrm{MgO}$ nanoparticles on the hot deformation process of $\mathrm{Mg}$ alloys yet. Therefore, more in-depth investigations must be done in the future.

Based on our previous work [11], research on $x \mathrm{MgO} / \mathrm{Mg}-3 \mathrm{Zn}-0.2 \mathrm{Ca}(x=0.1,0.2,0.3$, $0.5 \mathrm{wt} \%$ ) composites shows that the $0.2 \mathrm{MgO} / \mathrm{Mg}-3 \mathrm{Zn}-0.2 \mathrm{Ca}$ composite exhibited the most favorable comprehensive properties. The addition of nano $\mathrm{MgO}$ particles improves the strength of alloy but results in no significant difference in plasticity. Therefore, the present study investigates the hot deformation behavior of $\mathrm{Mg}-3 \mathrm{Zn}-0.2 \mathrm{Ca}$ and $0.2 \mathrm{MgO} / \mathrm{Mg}-3 \mathrm{Zn}-0.2 \mathrm{Ca}$ through constitutive analysis and processing maps by running hot compression tests under a wide range of compressive temperatures and strain rate range. Meanwhile, microstructural evolution and deformation mechanisms were systematically analyzed. This study aims to understand the effects of nano $\mathrm{MgO}$ in plastic deformation and obtain the optimal processing parameters to optimize its mechanical properties, providing a guideline for post-processing and lay a foundation for clinical application.

\section{Materials and Methods}

Pure Mg (99.99\%) ingot, pure Zn (99.99\%) particles (Ke Wei company of Tianjin University Co. Ltd., Tianjin, China), Mg-Ca master alloy (with $25 \mathrm{wt} \% \mathrm{Ca}$ ) and $\mathrm{MgO}$ nanoparticles (obtained by Biomaterial Lab, Tianjin, China) were used as raw materials to prepare the Mg-3Zn-0.2Ca alloy (MZC) and the $0.2 \mathrm{MgO} / \mathrm{Mg}-3 \mathrm{Zn}-0.2 \mathrm{Ca}$ composite (MZCM); the chemical composition of the MZC and MZCM are summarized in Table 1. Raw materials were melted in an electric furnace under a mixed protection atmosphere of $99.6 \% \mathrm{~N}_{2}$ and $0.4 \% \mathrm{SF}_{6}$ at $720^{\circ} \mathrm{C}$, and then, $\mathrm{MgO}$ nanoparticles were added into the melted MZC. A high shear stirring unit (developed by BCAST, Brunel University, London) [18] was employed to disperse the $\mathrm{MgO}$ nanoparticles with a mandatory infiltration stirring rate as $3500 \mathrm{rpm}$ for $5 \mathrm{~min}$, and then the melt was cast in a cold steel mold at $690^{\circ} \mathrm{C}$. Afterwards, the cast ingots were subjected to homogenizing annealing at $420^{\circ} \mathrm{C}$ for $13 \mathrm{~h}$.

Table 1. The chemical components of the Mg-3Zn-0.2Ca alloy (MZC) and the $0.2 \mathrm{MgO} / \mathrm{Mg}-3 \mathrm{Zn}-0.2 \mathrm{Ca}$ composite (MZCM) (wt\%).

\begin{tabular}{ccccc}
\hline Materials. & Zn & Ca & MgO & Mg \\
\hline Mg-Zn-Ca (MZC) & 3 & 0.2 & - & Balance \\
n-MgO/Mg-Zn-Ca (MZCM) & 3 & 0.2 & - & Balance \\
\hline
\end{tabular}

The homogenized ingots were machined into cylindrical specimens with a diameter of $10 \mathrm{~mm}$ and a height of $15 \mathrm{~mm}$ for hot compression tests. The hot compression tests were performed on a Gleeble 1500 thermal simulation test machine (DSI Inc., Saint Paul, MN, USA) under the protection of argon. The samples were heated to the test temperature at a rate of $10^{\circ} \mathrm{C} / \mathrm{s}$ and held for $1 \mathrm{~min}$. 
Afterwards, the specimens suffered a hot compression under a temperature range from 523 to $673 \mathrm{~K}$ and a strain rate from 0.001 to $1 \mathrm{~s}^{-1}$, and stopped when the true strain reached 0.7. Finally, the specimens were quenched in water immediately. The stress-strain curves during the deformation process were recorded. Observation of the microstructure of as-cast specimens and compression specimens after chemical polishing and corrosion was performed using an optical microscope (OM) (OLYMPUS Inc., Tokyo, Japan) and a scanning electron microscope (SEM) (FEI Inc., Hillsboro, OR, USA). The chemical compositions of different phases were analyzed by the SEM equipped with energy dispersive X-ray spectroscopy (EDS). The dynamic recrystallization (DRX) fractions of the samples were calculated by ImageJ software (FEI Inc., Hillsboro, OR, USA).

\section{Results}

\subsection{Initial Microstructure Analysis}

Figure 1 shows the microstructure of homogenized MZC and MZCM. Compared with coarse grains in MZC (Figure 1a), finer and more uniform grains are observed in MZCM (Figure 1b). The average grain size of MZCM was calculated to be $67 \mu \mathrm{m}$, which is $43 \mu \mathrm{m}$ lower than that of MZC. The black particles (marked by the black circle in Figure $1 \mathrm{~b}$ and spectrum 3 in Figure $1 \mathrm{~d}$ ), with dimensions in the range of 1-27 $\mu \mathrm{m}$, distributed in grain boundaries and interior grains of MZCM, which are agglomerated nano MgO particles. Based on SEM and EDS analysis (Table 2), the strip second phases (spectrum 1 and spectrum 4) along the grain boundary are identified to be $\mathrm{Ca}_{2} \mathrm{Mg}_{6} \mathrm{Zn}_{3}$ phase, and the spherical second phases (spectrum 2 and spectrum 5) in the grains are $\mathrm{MgZn_{2 }}$ phase, which is also consistent with our previous study [11]. Additionally, the average sizes of $\mathrm{Ca}_{2} \mathrm{Mg}_{6} \mathrm{Zn}_{3}$ and $\mathrm{MgZn} 2$ phase in MZC are $41.9 \mu \mathrm{m}$ and $9.74 \mu \mathrm{m}$, respectively, and average sizes of $\mathrm{Ca}_{2} \mathrm{Mg}_{6} \mathrm{Zn}_{3}$ and $\mathrm{MgZn} 2$ phase in MZCM are $15.4 \mu \mathrm{m}$ and $2.6 \mu \mathrm{m}$, respectively, showing the dramatic refinement effects of added $\mathrm{MgO}$.

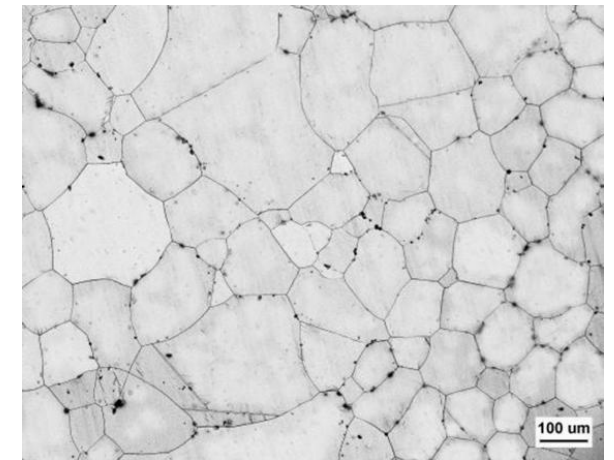

(a)

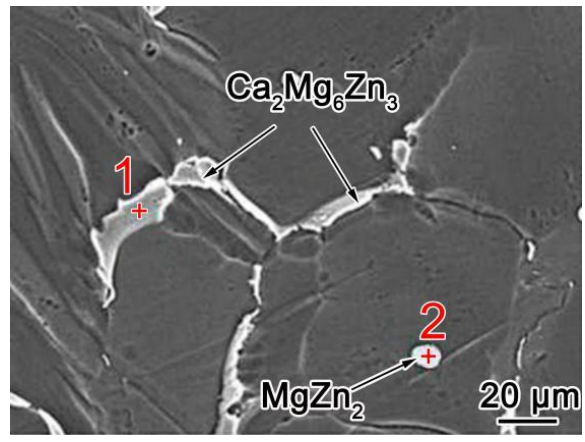

(c)

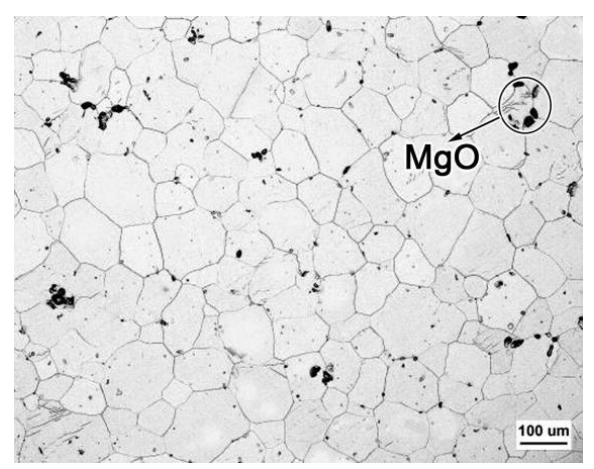

(b)

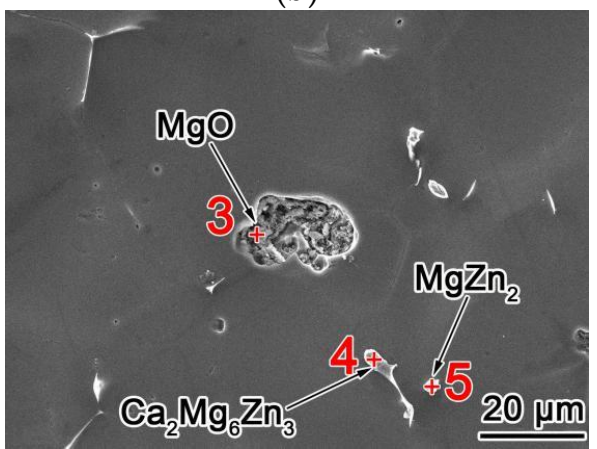

(d)

Figure 1. Optical microscope (OM) images $(\mathbf{a}, \mathbf{b})$ and SEM images $(\mathbf{c}, \mathbf{d})$ of homogenized MZC $(\mathbf{a}, \mathbf{c})$ and $\operatorname{MZCM}(\mathbf{b}, \mathbf{d})$. 
Table 2. Chemical composition of MZC and MZCM by EDS, wt\% (at.\%).

\begin{tabular}{ccccc}
\hline Spectrums & $\mathbf{M g}$ & $\mathbf{C a}$ & $\mathbf{Z n}$ & $\mathbf{O}$ \\
\hline$\# 1$ & $36.58(57.08)$ & $16.68(15.79)$ & $46.74(27.13)$ & - \\
$\# 2$ & $36.73(58.76)$ & $1.56(1.28)$ & $60.71(38.96)$ & - \\
$\# 3$ & $68.71(59.10)$ & - & - & $31.29(40.90)$ \\
$\# 4$ & $46.91(58.93)$ & $13.88(14.27)$ & $49.21(36.80)$ & - \\
$\# 5$ & $45.77(67.70)$ & $2.13(1.39)$ & $52.10(30.91)$ & - \\
\hline
\end{tabular}

\subsection{Flow Curves}

The typical true stress-strain $(\sigma-\varepsilon)$ curves of MZC and MZCM deformed up to a true strain of 0.7 at designed temperatures and strain rates are presented in Figure 2. All the flow stress curves increase initially to a peak value and then decrease to a steady state. Such flow behavior is a typical characteristic of hot working results from competitive deformation mechanisms between work-hardening and work-softening [19]. Especially, when the samples are compressed at a higher temperature or lower strain rate, the work softening dominates the deformation process and reaches a steady state at last. In contrast, the samples exhibit a great work-hardening rate at the initial stage, followed by moderate flow softening when deformed at a lower temperature or a higher strain rate. Figure 2 also shows that the flow stress of MZCM is lower than that of MZC under the same hot deformation condition in the temperature range of 523-623 K. However, it should be noted that the flow stress of MZCM is higher than that of MZC when deformed at $673 \mathrm{~K}$ and $0.1-1 \mathrm{~s}^{-1}$, which are caused by the hot cracking in MZC (Figure 15a).

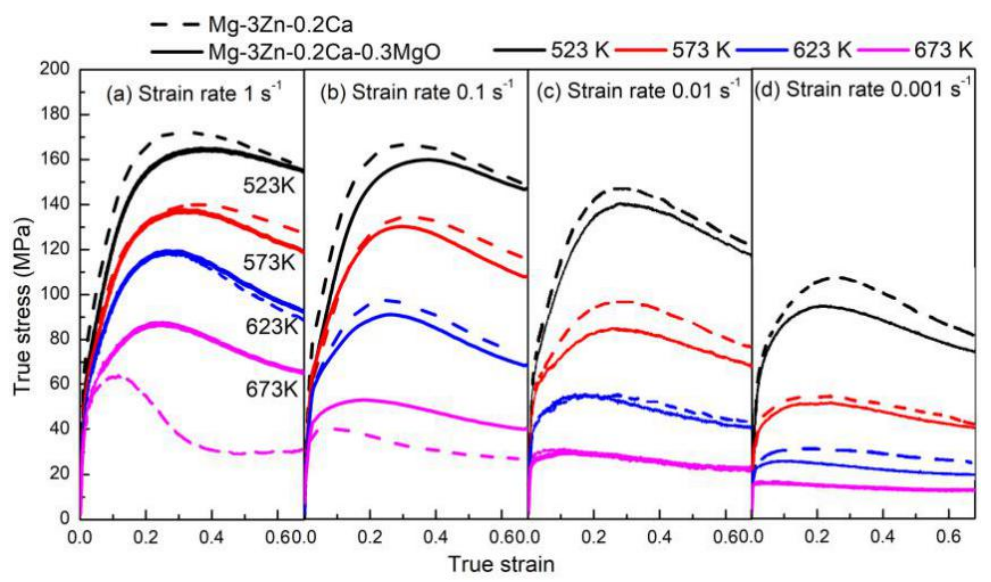

Figure 2. Ture stress-strain curves of MZC and MZCM at different temperatures with strain rates of (a) $0.001 \mathrm{~s}^{-1},(\mathbf{b}) 0.01 \mathrm{~s}^{-1}$, (c) $0.1 \mathrm{~s}^{-1}$ and (d) $1 \mathrm{~s}^{-1}$.

The peak stress values of MZC and MZCM at different strain rates and deformation temperatures are shown in Figure 3. It is demonstrated that the strain rate and deformation temperature have a significant influence on the peak stress of MZC and MZCM. The peak stress of the specimens decreases with increasing deformation temperature and decreasing strain rate. This is because the lower strain rate provides sufficient time for dislocation rearrangement and energy accumulation for DRX, and higher deformation temperatures increase the driving force and the mobility of grain boundaries [20]. 


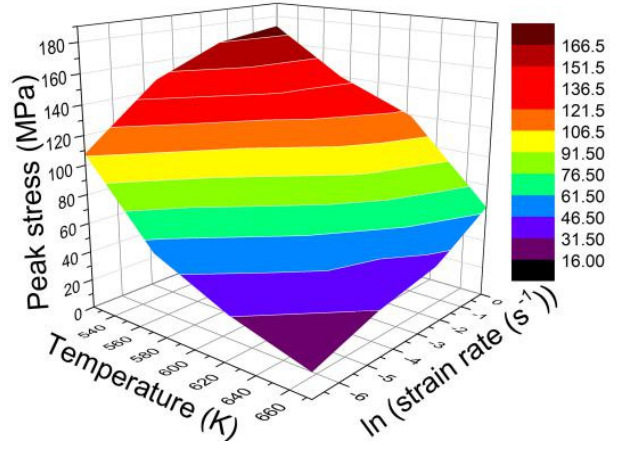

(a)

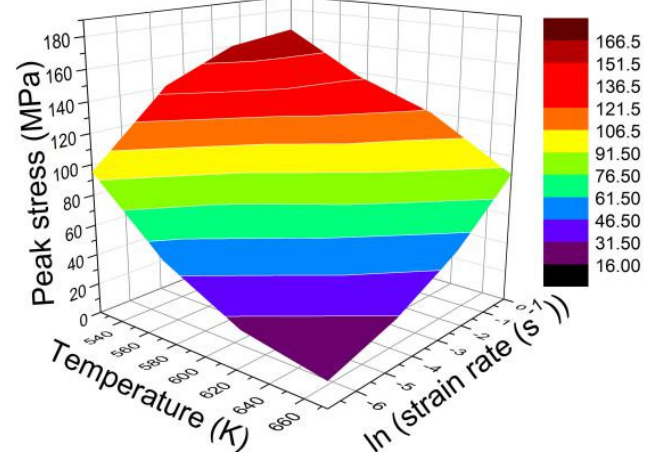

(b)

Figure 3. Variation of peak stresses of $\operatorname{MZC~(a)~and~} \operatorname{MZCM}(\mathbf{b})$ at different temperatures and strain rates.

\subsection{Constitutive Analysis}

Constitutive characteristics have been used to describe the relationship among the strain rate $(\dot{\varepsilon})$, deformation temperature $(T)$ and flow stress $(\sigma)$ for MZC and MZCM. A constitutive equation is helpful to study the effect of the addition of $\mathrm{MgO}$ on the temperature plastic deformation behavior of MZC. The corresponding equation is expressed as follows [21]:

$$
\dot{\varepsilon}=A[\sinh (\alpha \sigma)]^{n} \exp \left(-\frac{Q}{R T}\right)
$$

where $A$ is the material constant, $\alpha$ is the stress multiplier, $n$ is the stress exponent, $R$ is the gas constant $(8.314 \mathrm{~J} / \mathrm{mol} / \mathrm{K})$ and $Q$ is the activation energy for plastic flow $(\mathrm{KJ} / \mathrm{mol})$. In this part of the study, $\sigma$ is considered as the peak stress because the steady state is difficult to attain at high strain rate conditions. Equations (2) and (3) are applicable to low stress level $(\alpha \sigma<0.8)$ associated with power-law creep and high stress level $(\alpha \sigma>0.8)$ associated with power-law breakdown, respectively.

$$
\begin{gathered}
\dot{\varepsilon}=A_{1} \sigma^{n_{1}} \exp \left(-\frac{Q}{R T}\right) \\
\dot{\varepsilon}=A_{2} \exp (\beta \sigma) \exp \left(-\frac{Q}{R T}\right)
\end{gathered}
$$

where $A_{1}, A_{2}, n_{1}$ and $\beta$ are material constants and $\beta=\alpha n_{1}$. Taking natural logarithm on both sides of Equations (2) and (3), it can be seen that the value of $n_{1}$ could be derived from the slope of the linear equation between $\ln \dot{\varepsilon}$ and $\ln \sigma$, and the slope of the linear equation between $\ln \dot{\varepsilon}$ and $\sigma$ is the value of $\beta$. The average value of $\alpha$ was calculated from $n_{1}$ and $\beta$ for each alloy. Thus the average values of $\alpha$ obtained at various temperatures following the above procedure were 0.01420 and 0.01322 for MZCM and MZC, respectively.

$Q$ is an important physical parameter to characterize the deformation difficulty of materials under various conditions [22]. Taking the natural logarithm on both sides of Equation (1), $Q$ could be determined by differentiating the above equation:

$$
Q=R\left[\frac{\partial \ln \dot{\varepsilon}}{\partial \ln [\sinh (\alpha \sigma)]}\right]_{T}\left[\frac{\partial \ln [\sinh (\alpha \sigma)]}{\partial(1 / T)}\right]_{\dot{\varepsilon}}=R n s
$$

where $n$ is the average slope of the plots in the $\ln -\ln [\sinh (\alpha \sigma)]$ plots at different temperature and $s$ is the average slope of the lines of $\ln [\sinh (\alpha \sigma)]-1000 / T$ at different strain rates, as shown in Figure 4a-d. As such, the average value of $n$ for MZCM is given by the average slopes of $\ln$ and $\ln [\sinh (\alpha \sigma)]$ which was calculated as 4.5081, while the average value of $Q$ for MZCM could be calculated as $150.3 \mathrm{~kJ} \cdot \mathrm{mol}^{-1}$ according to Equation (4). Similarly, the average values of $n$ and $Q$ for MZC are 5.1387 and $187.2 \mathrm{~kJ} \cdot \mathrm{mol}^{-1}$, respectively. Therefore, the $n$ and $Q$ values of MZCM are lower than those of MZC, 
indicating that MZCM is more easily deformed than MZC under the same hot deformation condition. Substituting the above measured values into Equation (1), the constitutive equations for the MZC and MZCM are eventually obtained as Equations (5) and (6), respectively.

$$
\begin{aligned}
& \dot{\varepsilon}=1.044 \times 10^{15}[\sinh (0.0132 \sigma)]^{5.14} \exp \left(-\frac{187.17}{R T}\right) \\
& \dot{\varepsilon}=9.598 \times 10^{10}[\sinh (0.0142 \sigma)]^{4.51} \exp \left(-\frac{150.32}{R T}\right)
\end{aligned}
$$

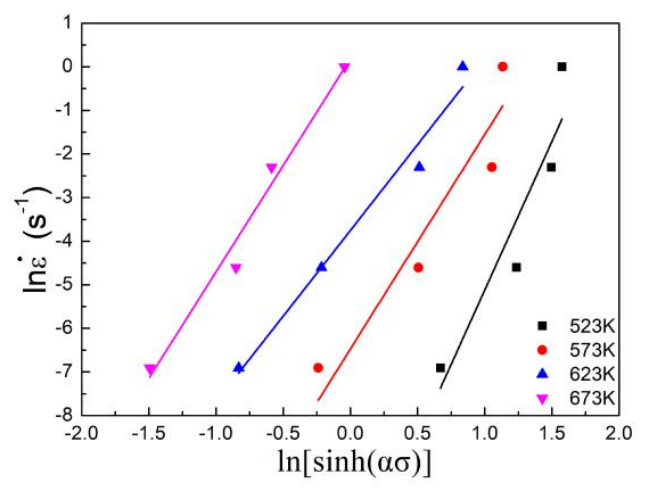

(a)

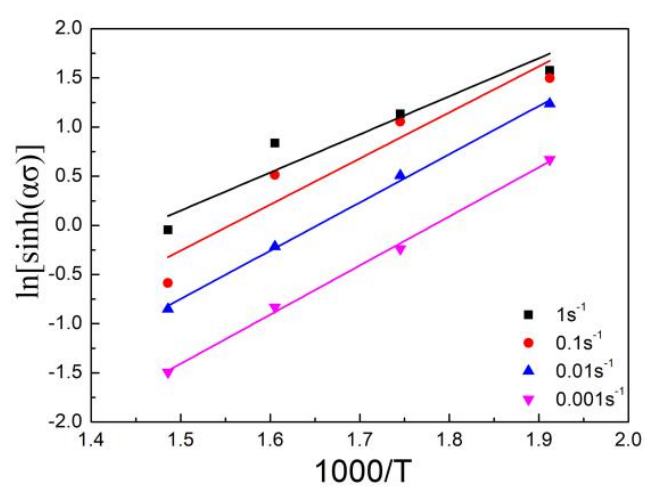

(c)

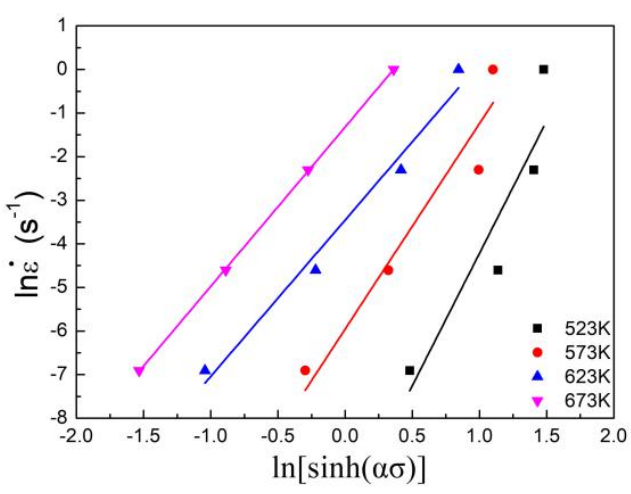

(b)

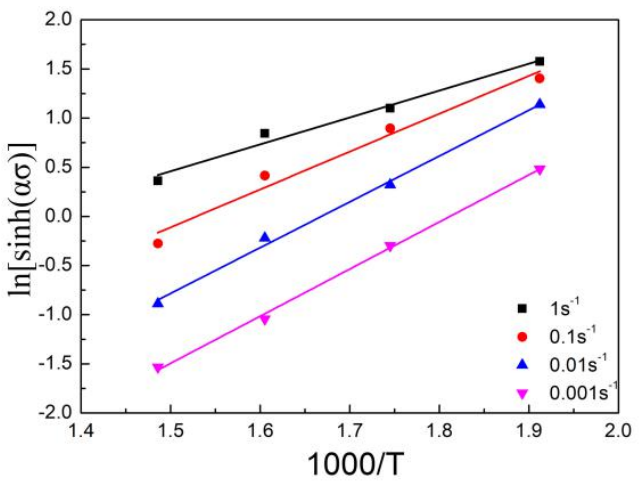

(d)

Figure 4. Plots of $\ln \dot{\varepsilon}-\ln [\sinh (\alpha \sigma)](\mathbf{a}, \mathbf{b})$ and $\ln [\sinh (\alpha \sigma)]-1000 / T(\mathbf{c}, \mathbf{d})$ for MZC $(\mathbf{a}, \mathbf{c})$ and MZCM $(\mathbf{b}, \mathbf{d})$.

Figure 5 shows the fitting plots between calculated and measured peak stress. It can be seen the correlation coefficient between calculated and measured peak stress for the MZC and MZCM are 0.988 and 0.987 , respectively. This means that the above constitutive equations could describe the hot deformation behavior of MZC and MZCM accurately. 


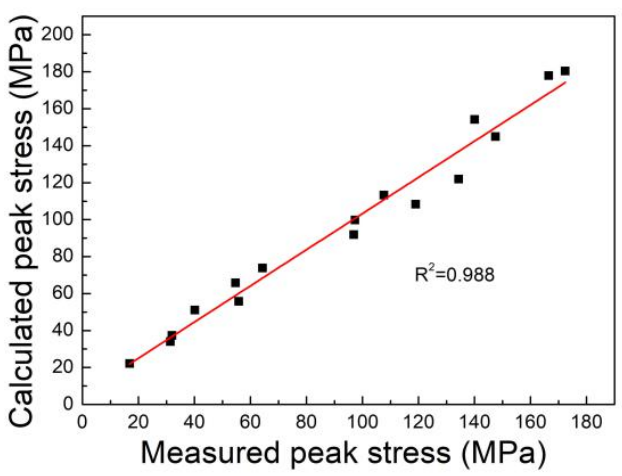

(a)

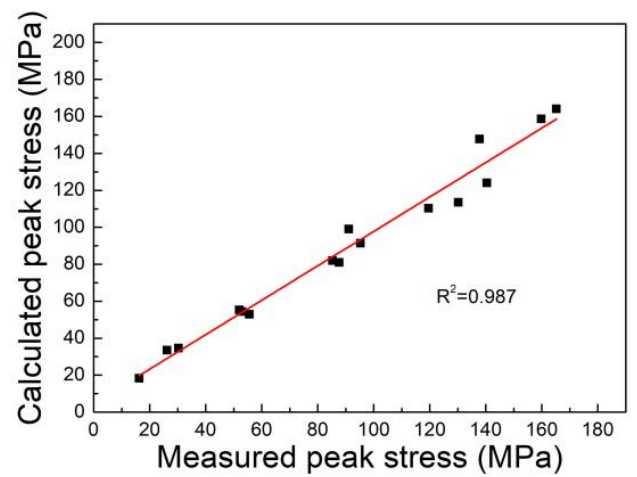

(b)

Figure 5. Comparison of the calculated and measured peak stress for MZC (a) and MZCM (b).

\subsection{Processing Maps}

To obtain the optimum hot deformation conditions, processing maps [23] were developed to investigate the workability of materials, which are the combination of an instability map onto a power dissipation map. When the alloy behaves as a power dissipator in the process of hot deformation, the generated power is mainly dissipated through plastic deformation and microstructural evolution. According to the dynamic materials model, power dissipation efficiency $(\eta)$ is defined as the characteristic of power dissipation of microstructural evolution during hot deformation, which is expressed as [24]:

$$
\eta=2 m /(m+1)
$$

where $m(=\partial \ln \sigma / \partial \ln \dot{\varepsilon})$ is the strain rate sensitivity exponent. The correlation between the $\eta$ values and deformation parameters (temperature and strain rate) represents a power dissipation map, which shows different domains associated with a specific microstructure process. However, $\eta$ alone cannot determine the workability of the material. An instability map is used to characterize the instability zones of the material during hot deformation. The instability criterion used to define the onset of flow instability is expressed as follows [25]:

$$
\xi(\dot{\varepsilon})=\frac{\partial \ln [m / m+1]}{\partial \ln \dot{\varepsilon}}+m \leq 0
$$

where $\xi(\dot{\varepsilon})$ is the instability parameter. The variation of the $\xi$ values with different temperatures and strain rates constitutes an instability map that defines the domains of flow instability $(\xi(\dot{\varepsilon})<0)$. The flow instability domains are always attributed to adiabatic shear bands, cracks or localized flow instabilities in the microstructure [26]. Finally, the processing map can be plotted by the superimposition of an instability map onto a dissipation map. A higher $\eta$ value in the map means that power dissipation provides more energy for the dynamic recovery (DRV) and DRX at a certain temperature and strain rate. A positive $\xi$ value and high $\eta$ value signify better workability of the materials. Thus, premium microstructure and excellent mechanical properties of the material are gained under this situation.

Figures 6 and 7 show the processing maps at strains of 0.1, 0.3, 0.5 and 0.7 for MZC and MZCM, respectively. The strains of $0.1,0.3$ and 0.5 represent the work-hardening stage, the balance stage between work-hardening and -softening and the work -oftening stage, respectively. The shaded areas reveal the flow instability regions while the unshaded areas reveal the flow stability regions. For the same material, the $\eta$ patterns at the strains of $0.1-0.7$ are similar in terms of contour shape, while the value of $\eta$ is different between MZC and MZCM. Furthermore, the distribution of instability regions varies with strains and materials. 


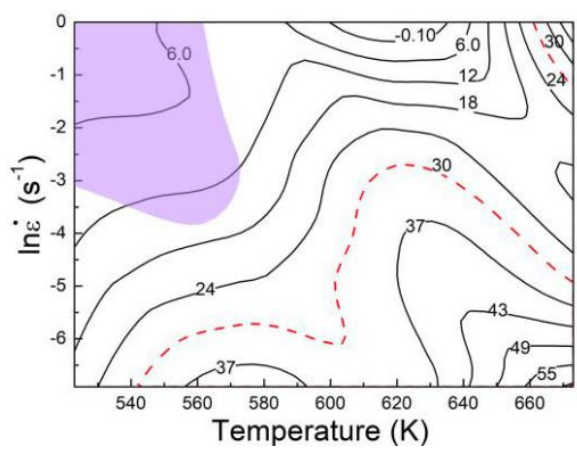

(a)

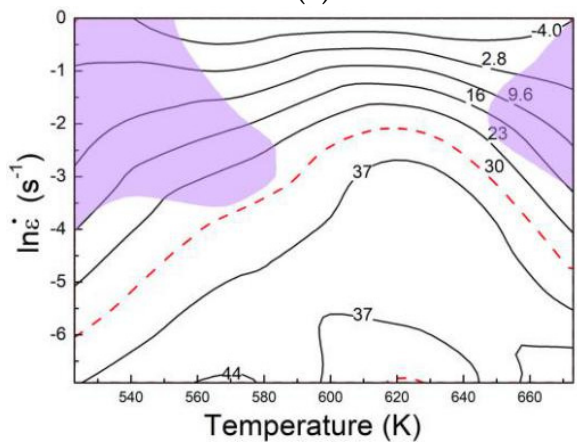

(c)

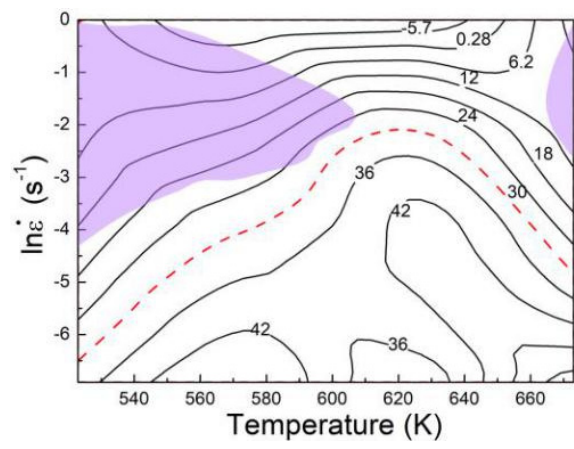

(b)

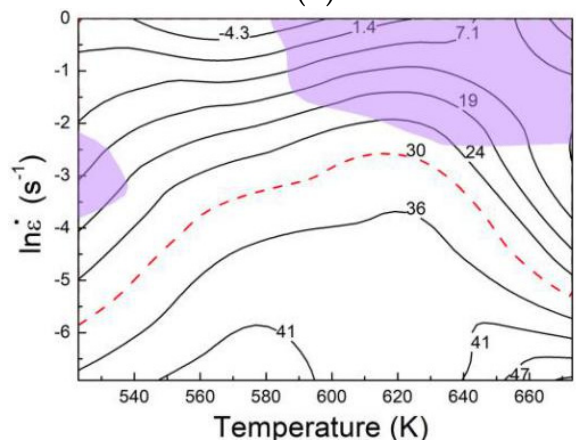

(d)

Figure 6. Processing maps of the MZC at the strains of (a) $0.1,(\mathbf{b}) 0.3,(\mathbf{c}) 0.5$ and (d) 0.7 .

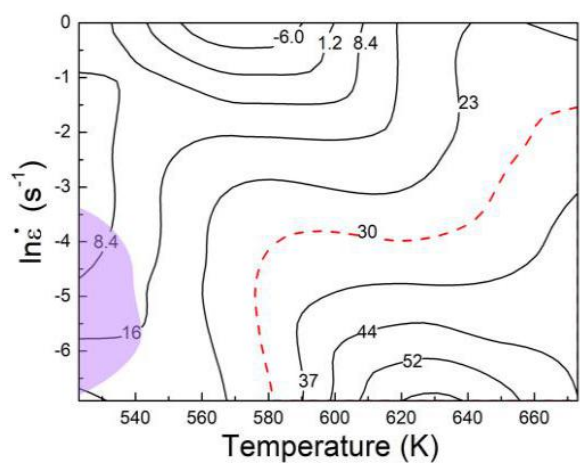

(a)

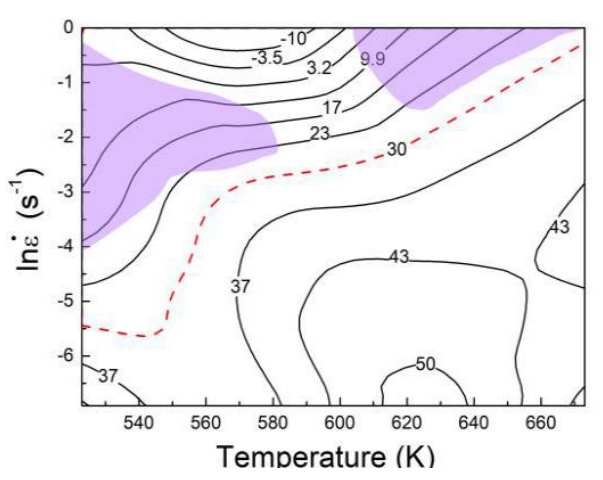

(c)

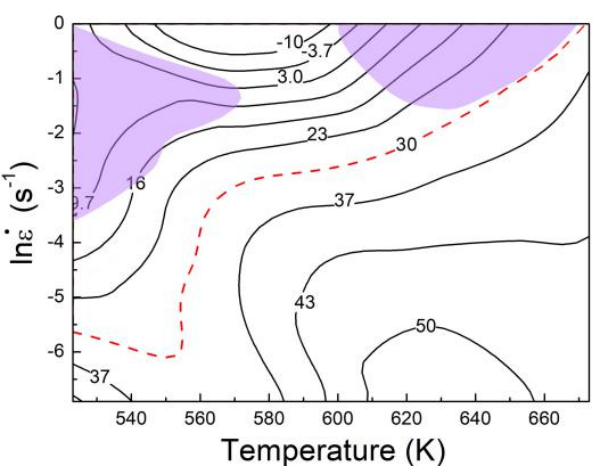

(b)

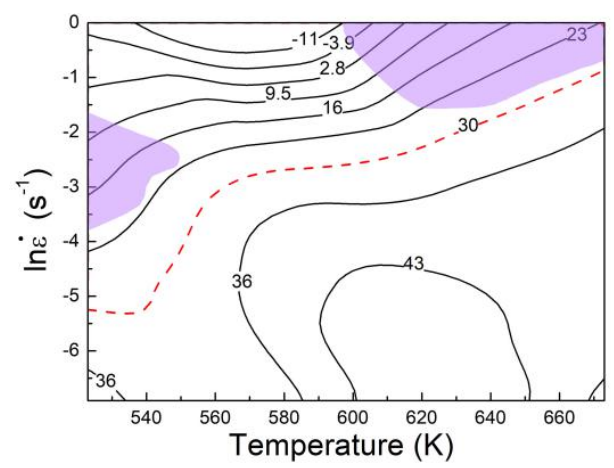

(d)

Figure 7. Processing maps of the MZCM at the strains of (a) 0.1 , (b) 0.3 , (c) 0.5 and (d) 0.7 .

As shown in Figures 6 and 7, the numbers marked in contour represents $\eta$ values in percentage. $\eta$ values ranging from 30 to $50 \%$ associated with DRX [25], and the boundaries of $\eta=30 \%$ are marked by red dotted lines. For both MZC and MZCM, the areas in the processing maps with $\eta$ values over $30 \%$ increase with increasing strain in a general trend, indicating that the transformation mechanism 
transfers from work-hardening to work-softening. Additionally, the maximum $\eta$ value in processing maps of MZCM is higher than that of MZC at certain strains, proving the microstructure of MZCM is more deeply influenced by dynamic recrystallization mechanisms. Processing maps at the strain of 0.7 present the stability state of the specimen during hot deformation. Thus, compared with MZC at the strain of 0.7 , the DRX region with $\eta$ values in the range of $30-50 \%$ MZCM is larger and the area of the whole instability region of MZCM is smaller. However, the area of the low-temperature high strain-rate instability region for MZCM is larger than that of MZC, and the area of the high-temperature high strain-rate instability region for MZCM is smaller than that of MZC. Therefore, the alleviative flow instability in the MZCM at high temperatures and high strain rates results from the DRX, which was promoted by the addition of nano $\mathrm{MgO}$. Meanwhile, it is worth noting that the instability region of MZCM at the low temperature is enlarged due to the stress concentration effects caused by nano $\mathrm{MgO}$.

\section{Discussion}

\subsection{Crystal Analysis}

As illustrated in Figure 8, the Mg matrix has a close-packed hexagonal structure (HCP) with lattice parameters of $a=0.321 \mathrm{~nm}$ and $c=0.521 \mathrm{~nm}$ [27], and the crystal structure of reinforcement $\mathrm{MgO}$ is face-center-cubic with lattice parameters of $a=0.421 \mathrm{~nm}$. Interface bonding status between matrix and reinforcement has a great influence on the properties of the composite. According to the lattice disregistry theory proposed by Bramfitt [28], the disregistry $(\delta)$ equation between nucleation phase and matrix is:

$$
\delta_{(h k l)_{n}}^{(h k l)_{s}}=\sum_{i=1}^{3} \frac{\left|\frac{\left(d_{[u v v]_{s}^{i}} \cos \theta\right)-d_{[u v v]_{n}^{i}}}{d_{[u v v]_{n}^{i}}}\right| \times 100}{3}
$$

where $(h k l)_{S}$ and $(h k l)_{n}$ are a low-index plane of the substrate and the nucleated solid, respectively, $[u v w]_{s}$ and $[u v w]_{n}$ are a low-index direction in $(h k l)_{s}$ and $(h k l)_{n}$, respectively, and $d_{[u v w] n}$ and $d_{[u v w] s}$ are the interatomic spacing along $[u v w]_{n}$ and $[u v w]_{s}$, respectively. According to the reported literature [28], the refinement effect of nucleation particles on a matrix is the best when $\delta$ is less than $6 \%$ and decreases when $\delta$ is between $6 \%$ and $12 \%$. Thus, based on Equation (9), the calculated $\delta$ (Table 3) between $\mathrm{MgO}$ nucleation particles and the $\mathrm{Mg}$ matrix is much lower than $6 \%$, indicating good lattice matching between them. Therefore, $\mathrm{MgO}$ particles can be used as an effective and stable nucleation core of the Mg matrix, which promotes the DRX process in MZCM during deformation. Meanwhile, fine grain structure and work-softening effects resulting from the DRX process endow stable deformation onto MZCM. Moreover, small interface disregistry between $\mathrm{MgO}$ particles and $\mathrm{Mg}$ matrix means great deformation compatibility, which benefits the plasticity of MZCM.
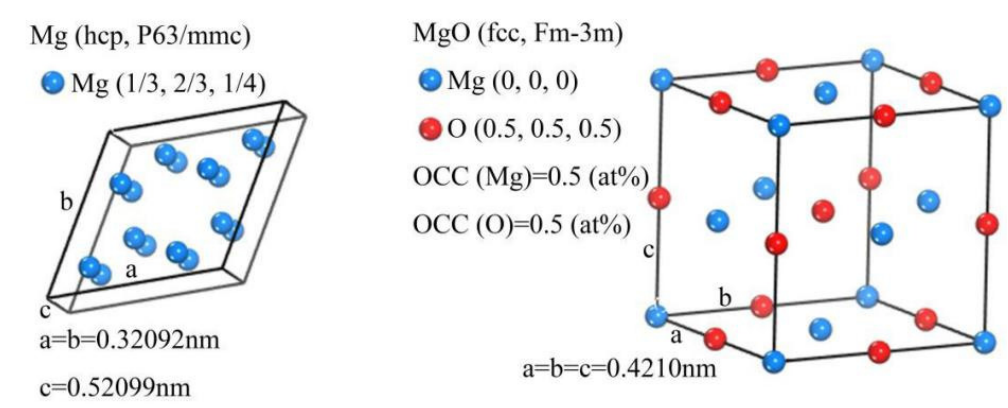

Figure 8. Crystal structure simulations of $\mathrm{Mg}$ and $\mathrm{MgO}$. 
Table 3. Possible coherent interfaces of $\mathrm{Mg}$ and $\mathrm{MgO}$.

\begin{tabular}{|c|c|c|c|c|c|}
\hline \multirow{2}{*}{ Number } & \multicolumn{2}{|c|}{ Mg } & \multicolumn{2}{|c|}{$\mathrm{MgO}$} & \multirow{2}{*}{$\delta / \%$} \\
\hline & $d / \mathrm{nm}$ & $(h k l)$ & $d / \mathrm{nm}$ & $(h k l)$ & \\
\hline 1 & 0.13867 & (200) & 0.14891 & (220) & 1.87 \\
\hline 2 & 0.13613 & (112) & 0.21056 & (200) & 1.07 \\
\hline 3 & 0.13396 & (201) & 0.14891 & (220) & 2.91 \\
\hline 4 & 0.13613 & (112) & 0.14891 & (220) & 1.05 \\
\hline
\end{tabular}

\subsection{Flow Behavior}

Figure 9 shows the typical work-hardening rate $(\theta=\mathrm{d} \sigma / \mathrm{d} \varepsilon)$-flow stress curve which further describes the hot deformation process of materials [29]. The three stages of the plot are divided by the critical stress $\left(\sigma_{\mathrm{c}}\right)$, peak stress $\left(\sigma_{\mathrm{p}}\right)$ and steady state stress $\left(\sigma_{\mathrm{ss}}\right)$, which are referred to as the significant work-hardening stage (I), the balance stage between the work-hardening and -softening (II) and the dynamic softening stage (III), respectively [30]. Saturated stress $\left(\sigma_{\text {sat }}\right)$ suggests a balance between the work-hardening and DRV while the stress for maximum softening rate $\left(\sigma^{*}\right)$ corresponds to the stress with minimum $\theta$. Steady-state flow behavior is achieved when work-hardening and dynamic softening (DRX and DRV) reach a dynamic balance at $\sigma_{\mathrm{ss}}$.

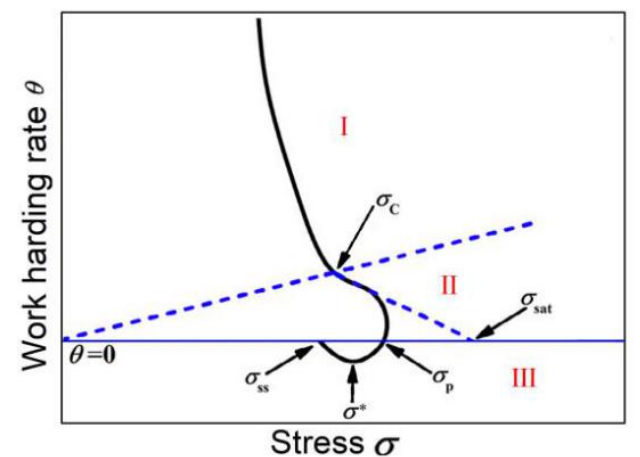

Figure 9. Schematic of the relation between working-hardening rate and flow stress.

The work-hardening rate $(\theta=\mathrm{d} \sigma / \mathrm{d} \varepsilon)$-flow stress curves calculated from the true stress-strain curves of MZC and MZCM are shown in Figures 10 and 11, respectively. According to the above characteristics of the schematic (Figure 9), when deformed at $623-673 \mathrm{~K}$ and $1 / \mathrm{s}$, the area enclosed by $\theta$ $=0$ and $\theta-\sigma$ curves $(\theta<0)$ is larger than the area under other deformation conditions for MZC and MZCM, indicating the unstable status of under this condition. Moreover, the aforementioned area of MZC is larger than that of MZCM under the same condition, indicating that the larger instability area of MZC than that of MZCM. This is consistent with the results of the above mentioned processing maps at the strain of stability state.

The $\sigma_{\mathrm{c}}$ on the spinodal of the curves in Figures 10 and 11 indicates the dislocation density in a material [31], which increases with increasing strain rates or decreasing deformation temperature for MZC and MZCM in the general trend. The increase rates of the materials under certain temperature are calculated as $k_{\mathrm{p}}$ values in corresponding figures. When deformed at under $573 \mathrm{~K}$, the $\sigma_{\mathrm{c}}$ values of MZCN increase much more slowly than those of MZC with smaller $k_{\mathrm{p}}$, indicating lower stress and dislocation concentrations in MZCM. This is because the addition of $\mathrm{MgO}$ in MZCM refines the microstructure of it, especially the coarse $\mathrm{Ca}_{2} \mathrm{Mg}_{6} \mathrm{Zn}_{3}$ phase, which avoids brittle fractures forming in it. A reverse trend is shown when the deformation temperature is over $623 \mathrm{~K}$-the lower $\sigma_{\mathrm{c}}$ and $k_{\mathrm{p}}$ values of MZC which contribute to the unstable structure may be caused by the microcracks in it, which is consistent with the bigger unstable area of $\mathrm{MZC}$ in the processing map (Figure 6d). Importantly, compared with MZC, it is worth noting that the $\mathrm{k}_{\mathrm{p}}$ values of MZCM at higher temperatures (573-673 K) 
are not associated with increasing temperature, indicating that the addition of $\mathrm{MgO}$ endows the $\mathrm{MZCM}$ with a more stable deformation behavior and mechanism at higher temperatures.

The values of critical strain of the initiation of $\operatorname{DRX}\left(\varepsilon_{\mathrm{c}}\right)$, the strain corresponding to $\sigma_{\mathrm{p}}\left(\varepsilon_{\mathrm{p}}\right)$ and the ratio of $\varepsilon_{\mathrm{c}} / \varepsilon_{\mathrm{p}}$ at different deformation regimes for MZC and MZCM are listed in Tables 4 and 5, respectively. The results show that the values of $\varepsilon_{\mathrm{c}}$ and $\varepsilon_{\mathrm{p}}$ increase with the increasing strain rate under the same deformation temperature. This is because the higher strain rate cannot provide sufficient nucleation time for DRX in the alloy, resulting in a dramatic work-hardening effect due to the higher dislocation density [32]. A decrease in the $\varepsilon_{\mathrm{c}}$ and $\varepsilon_{\mathrm{p}}$ values of MZC and MZCM is also observed with increasing deformation temperature under the same strain rate. A high deformation temperature promotes annihilation and rearrangement of dislocations at grain boundaries [33], which boosts the nucleation and growth rate of DRX grains. Meanwhile, a higher temperature decreases the critical resolved shear stress (CRSS) of the non-basal slip system [34] of HCP structure alloy, which decreases the work-hardening effects by enhancing the cross slipping in the alloy.

In general, values of $\varepsilon_{\mathrm{c}} / \varepsilon_{\mathrm{p}}$ in the range of $0 \sim 1$ indicate the onset of DRX at a given deformation condition $[35,36]$. The average value of $\varepsilon_{\mathrm{c}} / \varepsilon_{\mathrm{p}}$ for MZC and MZCM is 0.734 and 0.694 , respectively, which is close to the $\varepsilon_{\mathrm{c}} / \varepsilon_{\mathrm{p}}$ value for many metals, around 0.8 [37]. The lower average $\varepsilon_{\mathrm{c}} / \varepsilon_{\mathrm{p}}$ value of MZCM reveals that the DRX of MZCM occurs at a lower strain. According to the particle-stimulated nucleation (PSN) mechanism, agglomerated $\mathrm{MgO}$ nanoparticles with a diameter larger than $1 \mu \mathrm{m}$ (Figure $1 \mathrm{~b}$ ) promote DRX of MZCM by producing local high-density dislocations during deformation [38]. Therefore, the addition of nano MgO promotes the DRX of MZCM. This also explains why the flow stress of MZC is higher than that of MZCM under the same hot deformation conditions (Figure 2).

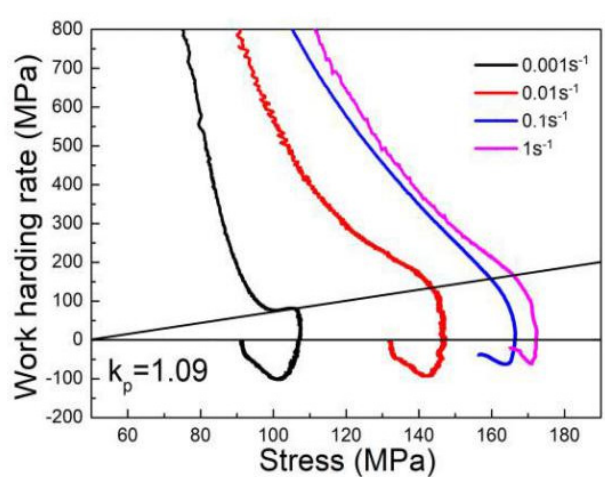

(a)

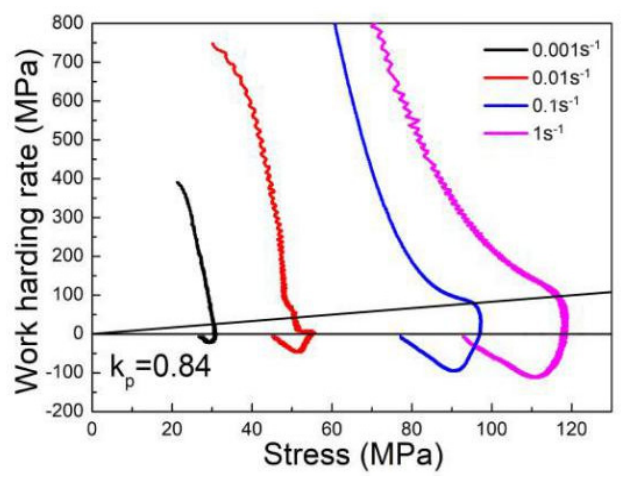

(c)

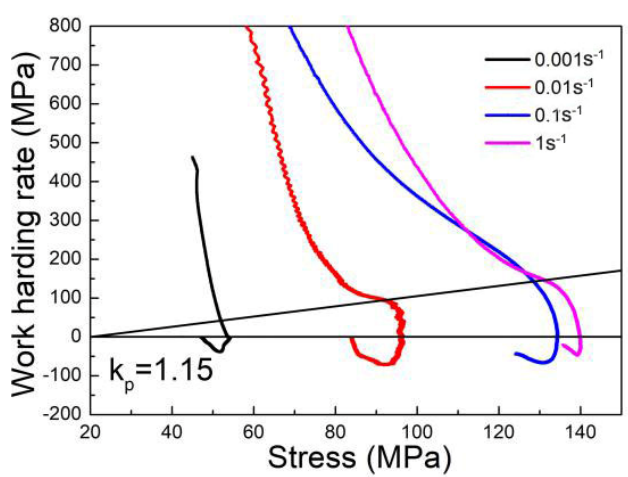

(b)

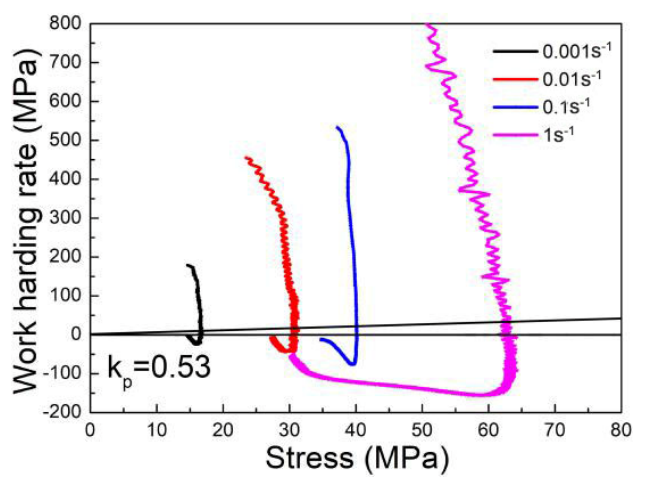

(d)

Figure 10. Variation of the work-hardening rate $\theta$ with flow stress $\sigma$ for MZC at different temperatures: (a) $523 \mathrm{~K}$; (b) $573 \mathrm{~K}$; (c) $623 \mathrm{~K}$ and (d) $673 \mathrm{~K}$. 


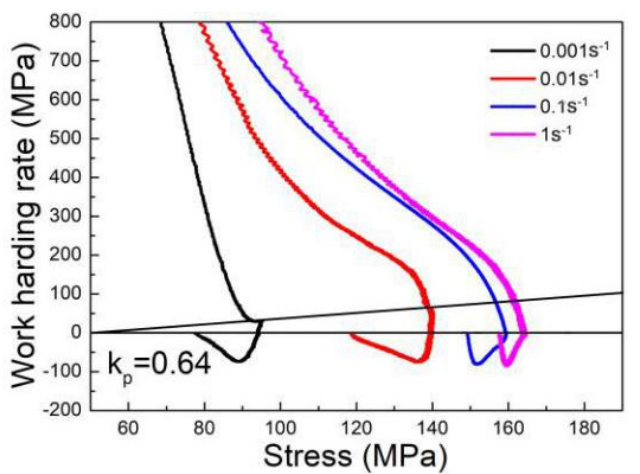

(a)

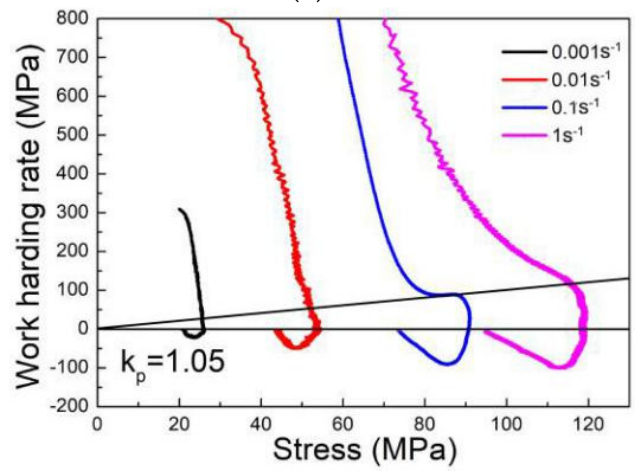

(c)

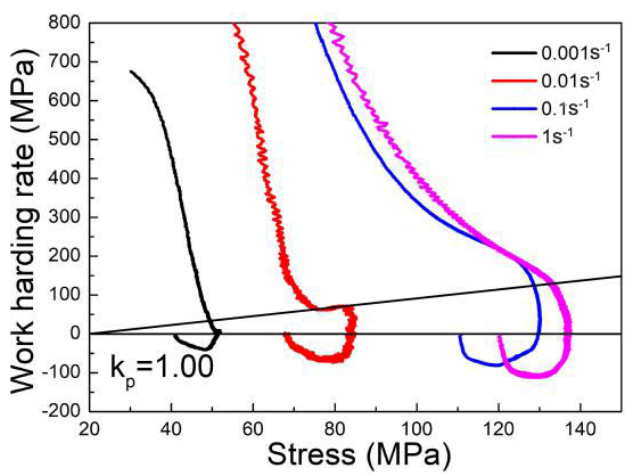

(b)

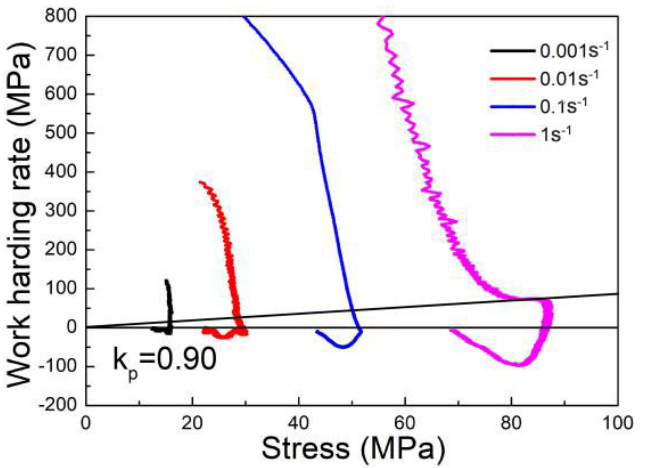

(d)

Figure 11. Variation of the work-hardening rate $\theta$ with flow stress $\sigma$ for MZCM at different temperatures: (a) $523 \mathrm{~K}$; (b) $573 \mathrm{~K}$; (c) $623 \mathrm{~K}$ and (d) $673 \mathrm{~K}$.

Table 4. Values of $\varepsilon_{\mathrm{c}}, \varepsilon_{\mathrm{p}}$ and $\varepsilon_{\mathrm{c}} / \varepsilon_{\mathrm{p}}$ under different deformation conditions for MZC and MZCM.

\begin{tabular}{cccccccc}
\hline \multirow{2}{*}{ Temperature/K } & $\dot{\varepsilon} / \mathbf{s}^{-1}$ & \multicolumn{3}{c}{ MZC } & & \multicolumn{3}{c}{ MZCM } \\
\cline { 3 - 7 } & & $\varepsilon_{\mathbf{c}}$ & $\varepsilon_{\mathbf{p}}$ & $\varepsilon_{\mathbf{c}} / \varepsilon_{\mathbf{p}}$ & $\varepsilon_{\mathbf{c}}$ & $\varepsilon_{\mathbf{p}}$ & $\varepsilon_{\mathbf{c}} / \varepsilon_{\mathbf{p}}$ \\
\hline \multirow{5}{*}{523} & 0.001 & 0.195 & 0.267 & 0.730 & 0.193 & 0.265 & 0.728 \\
& 0.01 & 0.207 & 0.296 & 0.699 & 0.208 & 0.305 & 0.682 \\
& 0.1 & 0.215 & 0.325 & 0.662 & 0.218 & 0.338 & 0.645 \\
& 1 & 0.229 & 0.338 & 0.678 & 0.239 & 0.342 & 0.699 \\
573 & 0.001 & 0.093 & 0.122 & 0.762 & 0.099 & 0.161 & 0.615 \\
& 0.01 & 0.139 & 0.295 & 0.471 & 0.200 & 0.294 & 0.680 \\
& 0.1 & 0.211 & 0.322 & 0.655 & 0.215 & 0.314 & 0.685 \\
& 1 & 0.220 & 0.336 & 0.654 & 0.226 & 0.327 & 0.691 \\
623 & 0.001 & 0.087 & 0.110 & 0.791 & 0.073 & 0.117 & 0.624 \\
& 0.01 & 0.102 & 0.149 & 0.685 & 0.099 & 0.176 & 0.563 \\
& 0.1 & 0.178 & 0.281 & 0.633 & 0.211 & 0.284 & 0.743 \\
& 1 & 0.191 & 0.284 & 0.673 & 0.220 & 0.289 & 0.761 \\
673 & 0.001 & 0.057 & 0.065 & 0.877 & 0.054 & 0.067 & 0.806 \\
& 0.01 & 0.070 & 0.078 & 0.897 & 0.076 & 0.093 & 0.817 \\
& 0.1 & 0.074 & 0.079 & 0.937 & 0.088 & 0.140 & 0.629 \\
& 1 & 0.086 & 0.092 & 0.935 & 0.203 & 0.277 & 0.733 \\
\hline
\end{tabular}


Table 5. $\ln Z$ values of MZC and MZCM under different deformation conditions.

\begin{tabular}{ccccccccc}
\hline \multirow{2}{*}{$/ \mathbf{s}^{-\mathbf{1}}$} & \multicolumn{9}{c}{ MZC } & \multicolumn{5}{c}{ MZCM } \\
\cline { 2 - 9 } & $\mathbf{5 2 3} \mathbf{~ K}$ & $\mathbf{5 7 3 ~ K}$ & $\mathbf{6 2 3} \mathbf{~ K}$ & $\mathbf{6 7 3 ~ K}$ & $\mathbf{5 2 3} \mathbf{~}$ & $\mathbf{5 7 3 ~}$ & $\mathbf{6 2 3} \mathbf{~}$ & $\mathbf{6 7 3} \mathbf{~}$ \\
\hline 1 & 45.3 & 41.4 & 38.1 & 35.2 & 34.6 & 31.6 & 29.0 & 26.9 \\
0.1 & 43.0 & 39.1 & 35.8 & 32.9 & 32.3 & 29.3 & 26.7 & 24.6 \\
0.01 & 40.7 & 36.8 & 33.5 & 30.6 & 29.9 & 26.9 & 24.4 & 22.3 \\
0.001 & 38.4 & 34.5 & 31.2 & 28.3 & 27.7 & 24.6 & 22.1 & 19.9 \\
\hline
\end{tabular}

\subsection{Deformation Mechanism}

The values of average $Q$ of MZC and MZCM are $187.2 \mathrm{~kJ} \cdot \mathrm{mol}^{-1}$ and $150.3 \mathrm{~kJ} \cdot \mathrm{mol}^{-1}$, respectively, and the average values of $n$ for MZC and MZCM are 5.1387 and 4.5081. The $n$ and $Q$ values of MZCM are lower than those of $\mathrm{MZC}$, indicating that the addition of nano $\mathrm{MgO}$ particles decreases the stress sensitivity and deformation resistance for thermal deformation and improves the plasticity of the MZC [39]. This is because the addition of nano $\mathrm{MgO}$ particles in MZCM results in the formation of large quantities of non-equilibrium grain boundaries, which provide an additional driving force for MZCM during the compressive deformation [40]. Additionally, the addition of nano $\mathrm{MgO}$ particles in MZCM promotes the DRX, which reduces the threshold of deformation resistance of MZCM.

The compression deformation mechanism is also determined by stain rate sensitivity exponent. Figure 12 shows the strain rate sensitivity exponent $m$ of MZC and MZCM at different temperatures, which was calculated according to the slope of the linear equation between $\ln \sigma$ and $\ln \dot{\varepsilon}$. The value of $m$ reflects the ability of materials to suppress local necking. Generally, elongations of the alloys increase with increasing the $m$ value. As shown in Figure 12, the $m$ values of MZC and MZCM range from 0.07 to 0.21 under the corresponding temperature and strain rate ranges, suggesting that the dislocation climb is the dominant mechanism during compressive deformation [40]. As shown in Figure 12, the $m$ value of MZC and MZCM increases with the increase in deformation temperature, resulting from the more thermally activated annihilation of lattice dislocation effect in grain boundaries or adjacent zones under higher compression temperatures [41]. Compared to MZC, $m$ values of MZCM are higher at the same deformation temperature, indicating higher elongation of MZCM than of MZC. This is attributed to the higher grain boundary density in MZCM (Figure 1a,b), which benefits the plasticity of MZCM by grain boundary sliding [42]. Furthermore, the higher grain boundary density of MZCM accelerates the annihilation of positive and negative dislocations at grain boundaries in it, resulting in enhancement of elongation.

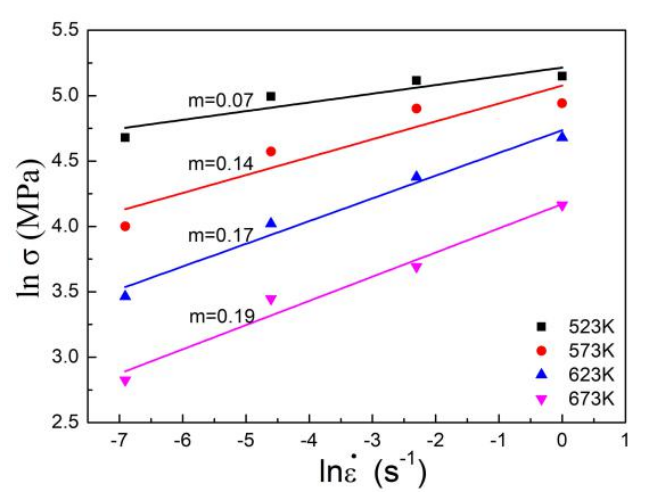

(a)

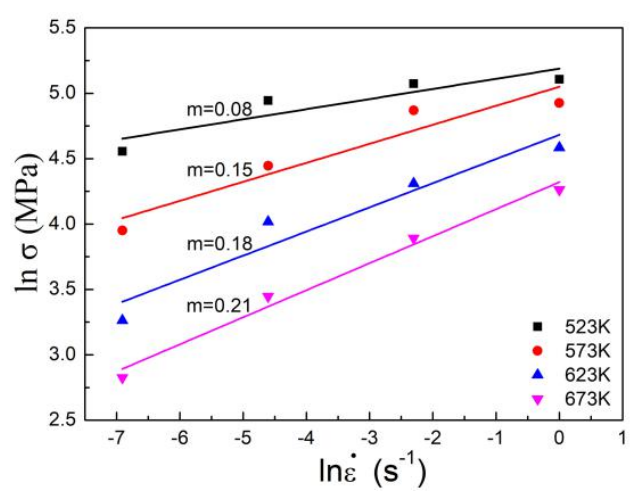

(b)

Figure 12. Strain rate sensitivity of (a) MZC and (b) MZCM.

\subsection{Microstructure Evolution}

The Zener-Hollomon $(Z)$ parameter is an important parameter for the characterization of the process of hot deformation for metallic materials. The $Z$ parameter is a deformation rate factor for 
temperature compensation which integrates the effects of deformation temperature and strain rate [43]. $\mathrm{Z}$ can be expressed by temperature and strain rate as:

$$
Z=\dot{\varepsilon} \exp \left(\frac{Q}{R T}\right)
$$

Then, $\ln Z$ values are obtained according to Equation (10), as shown in Table 5. The $Z$ parameter acts as a critical indicator of microstructure evolution under specific deformation conditions. Thus, based on the results of the processing maps and $Z$ parameter, DRX behaviors and microstructure evolution of MZC and MZCM are investigated. According to Table 5, the $Z$ value decreased with the increase in deformation temperature or the decreasing strain rate. DRX fraction can be estimated by flow stress and $Z$ parameter [29], indicating that the DRX fraction is sensitive to the $Z$ parameter. The $Z$ value of MZCM is lower than that of $M Z C$, and fine and equiaxed dynamic recrystallized grains (Figure 14) are obtained at a relatively low $Z$ value, indicating that a higher $Z$ value should not be taken during the process of hot deformation.

As shown in Figure 13, MZC and MZCM were compressed at $523 \mathrm{~K}_{\text {and }} 0.1 \mathrm{~s}^{-1}$, which correspond to a relatively high $Z$ value condition. According to the processing map at the strain of 0.7 (Figures 6d and 7d), the flow instability occurs both in MZC and MZCM under this low-temperature high strain-rate deformation condition. As no obvious dynamic recrystallized grains were observed in both specimens, indicating the dominance of work-hardening for these two materials. According to Figure 13, twinning is the main deformation behavior. Because of the poor work-softening provided by the DRX, serious stress concentration generates at the interface between twins and grain boundaries in MZC and MZCM (marked by black circles in Figure 13), which hinders the base-slip and result in microcracks. Importantly, the area of the low-temperature high strain-rate instability region for MZCM is larger than that of MZC (Figures $6 \mathrm{~d}$ and 7d). This is because MZCM is susceptible to local dislocation tangling because of the addition of $\mathrm{MgO}$, which induces local stress concentration easily and then results in microcracks. It is worth noting that the extension distance of microcracks of MZC is longer than that of MZCM, attributed to the hindered effects of high-density grain boundaries and nano $\mathrm{MgO}$ in MZCM. Moreover, it can be observed that the grains of MZCM are much more deformed than those of MZC. This is because the larger scaled $\mathrm{Ca}_{2} \mathrm{Mg}_{6} \mathrm{Zn}_{3}$ phases distributed along grain boundaries (Figure 1) increase the deformation resistance of MZC. Thus, the flow stress of MZCM is lower than that of MZC under this condition (Figure 2).

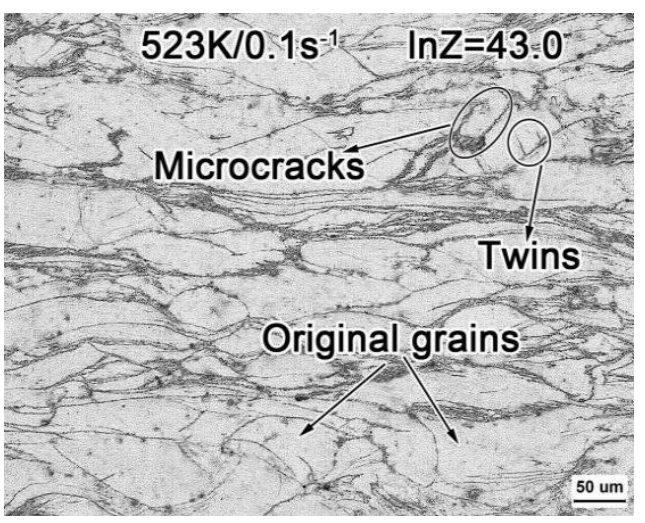

(a)

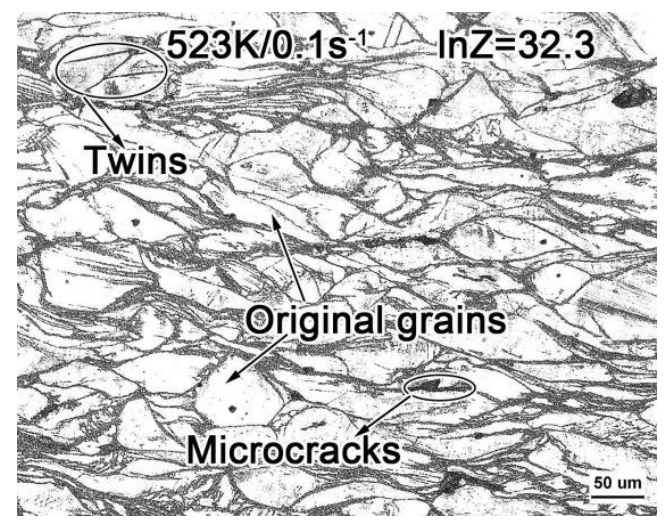

(b)

Figure 13. Microstructures of MZC (a) and MZCM (b) deformed at $523 \mathrm{~K} / 0.1 \mathrm{~s}^{-1}$.

Figure 14 shows the microstructure evolution in flow stability regions of MZC and MZCM deformed under different deformation conditions. As shown in Figure $14 a, b$, the necklace structure along the original grain boundaries at $623 \mathrm{~K}$ and $0.1 \mathrm{~s}^{-1}$ is observed, showing that a typical DRX feature initiates at grain boundaries, and the average grain size of MZCM and MZC are $2.6 \mu \mathrm{m}$ and $2.8 \mu \mathrm{m}$. 
Compared to Figure 13, DRX in both materials is promoted with the rise of deformation temperature, which is attributed to the improved mobility of dislocations in grain boundary due to the enhanced atomic diffusion at high temperature. The DRX fraction of MZCM (26.6\%) is higher than that of MZC $(15.7 \%)$, attributing to the higher grain boundary density and heterogeneous nucleation effects of $\mathrm{MgO}$, which provide more nuclear sites for dynamic recrystallized grains.

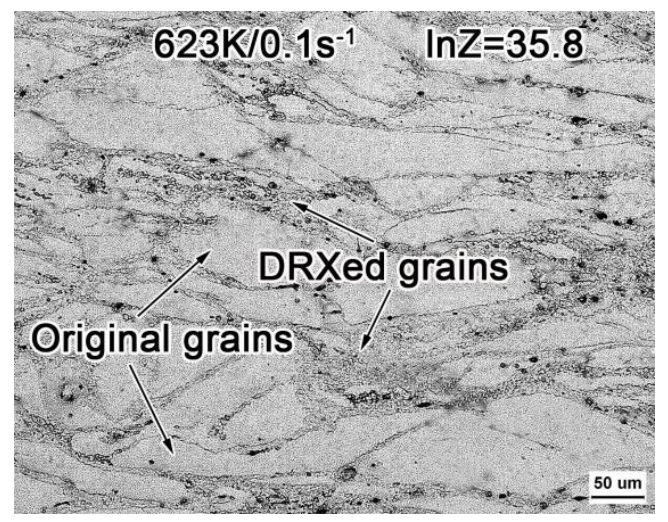

(a)

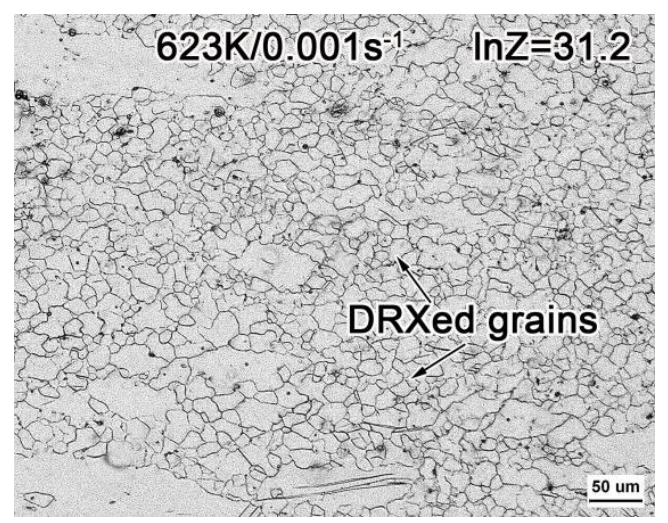

(c)

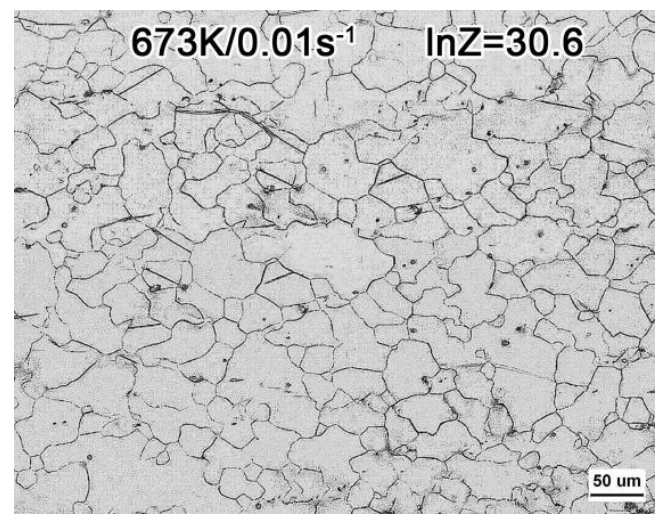

(e)

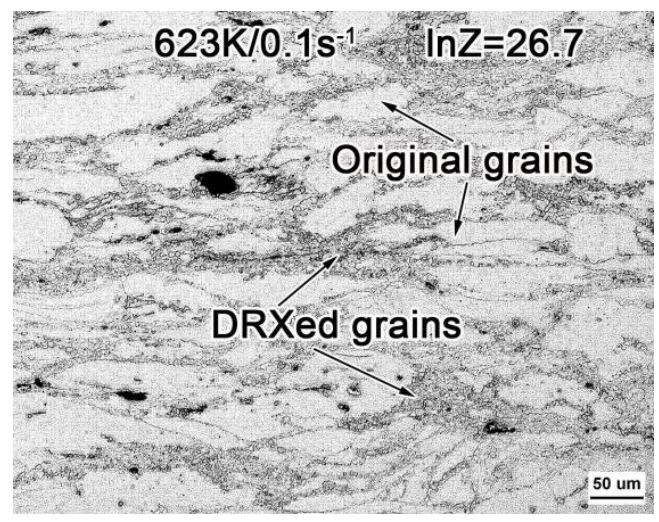

(b)

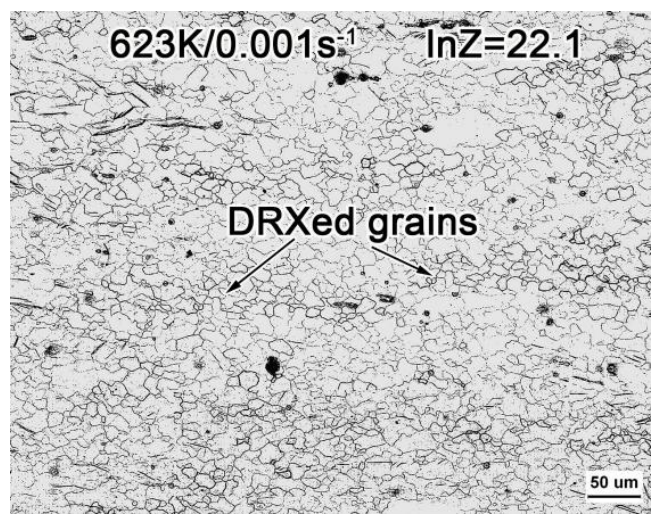

(d)

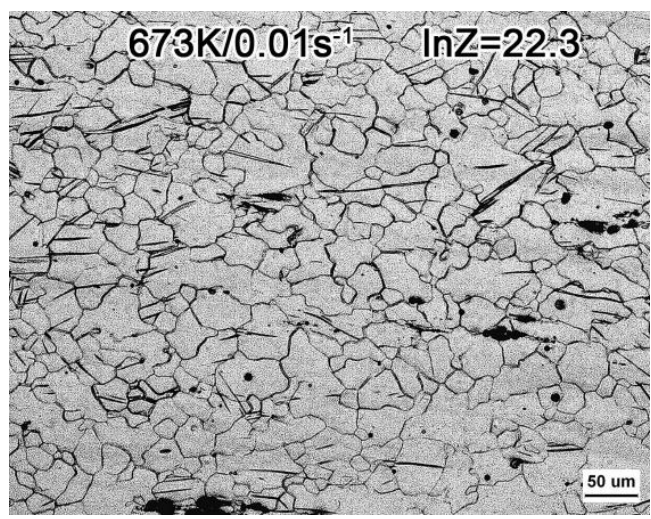

(f)

Figure 14. Microstructures of $\operatorname{MZC}(\mathbf{a}, \mathbf{c}, \mathbf{e})$ and $\operatorname{MZCM}(\mathbf{b}, \mathbf{d}, \mathbf{f})$ deformed at $(\mathbf{a}, \mathbf{b}) 623 \mathrm{~K} / 0.1 \mathrm{~s}^{-1}$, (c,d) $623 \mathrm{~K} / 0.001 \mathrm{~s}^{-1}$ and $(\mathbf{e}, \mathbf{f}) 673 \mathrm{~K} / 0.01 \mathrm{~s}^{-1}$.

The typical microstructures of MZC and MZCM at $623 \mathrm{~K}$ and $0.001 \mathrm{~s}^{-1}$ are shown in Figure $14 \mathrm{c}, \mathrm{d}$, respectively, which correspond to a high efficiency of power dissipation in the processing maps. Compared to Figures 13 and 14a,b, low strain rates leave sufficient time for DRX process, thus a uniform 
and equiaxed grain structure can be observed. The average DRX grain size of MZCM is $13.1 \mu \mathrm{m}$, which is more uniform and finer than that of MZC $(18.1 \mu \mathrm{m})$. This phenomenon is mainly ascribed to the addition of nano $\mathrm{MgO}$ particles, which limit the growth of crystallized grains in MZCM by pinning the grain boundaries during hot deformation. Under this deformation condition, the DRX fractions of MZCM and MZC are about $98.4 \%$ and $85.2 \%$, respectively, which benefits the DRX of MZCM a lot and thus decreases the flow stress (Figure 2) of it. Figure 14e,f show the microstructures of alloy deformed at $673 \mathrm{~K}$ and $0.01 \mathrm{~s}^{-1}$. Compared with Figure $14 \mathrm{c}, \mathrm{d}$, the average grain sizes of MZC and MZCM are $32.2 \mu \mathrm{m}$ and $28.1 \mu \mathrm{m}$, respectively. This is because a higher deformation temperature provides sufficient energy for dynamic recrystallized grains to grow continuously, resulting in overgrowth, especially for MZC, which lowers the flow stress of materials.

Figure 15 presents the microstructure of the edge region of MZC and MZCM at $673 \mathrm{~K}$ and $0.1 \mathrm{~s}^{-1}$, which corresponds to the flow instability domains for MZC and stability domains for MZCM. Compared with MZCM, higher density twins in MZC prevail the severe local deformation in the alloy. This is because the larger scaled $\mathrm{Ca}_{2} \mathrm{Mg}_{6} \mathrm{Zn}_{3}$ phase particles (Figure 1c) distributed along the grain boundaries cause serious stress concentration around them under the high strain rate of $0.1 \mathrm{~s}^{-1}$, which results in nucleation and extension of microcracks easily. Thus, the MZC fails to reach its intrinsic flow stress because of early fracture, resulting in low flow stress and the following plunge in stress in the stress-strain curve (Figure 2) for this condition. For MZCM, fewer twins indicate the uniform distribution of stress in it. This results from the fine grains and secondary phases refined by nano $\mathrm{MgO}$ in MZCM (Figure 1b,d), which decreases the deformation resistance and stress concentration in it. Therefore, no plastic instability happens for MZCM at $673 \mathrm{~K}$ and $0.1-1 \mathrm{~s}^{-1}$, and the flow stress of MZCM is higher than that of MZC.

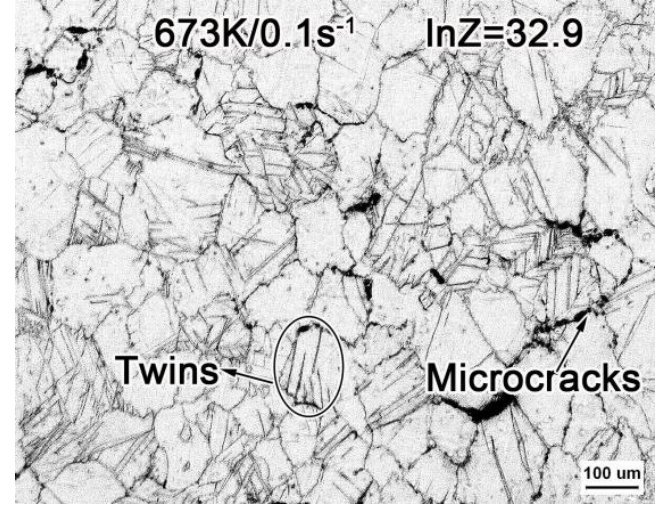

(a)

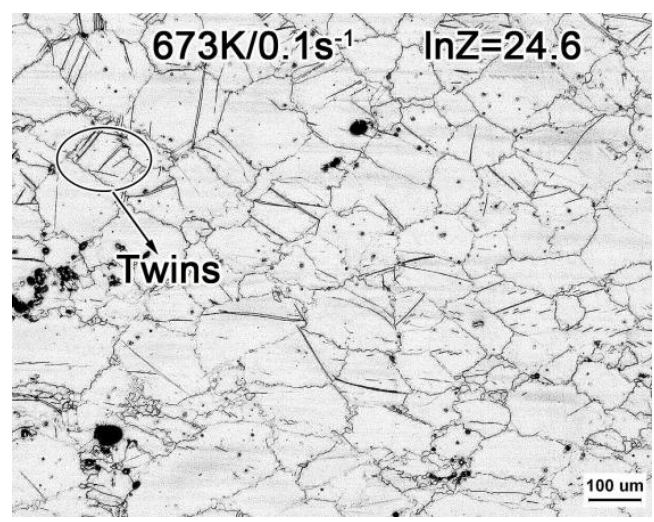

(b)

Figure 15. Microstructures of MZC (a) and MZCM (b) deformed at $673 \mathrm{~K} / 0.1 \mathrm{~s}^{-1}$.

Based on the above analysis, the optimum hot working condition for MZCM is determined to be 623-653 $\mathrm{K}$ and $0.01-0.001 \mathrm{~s}^{-1}$ with the peak value of power dissipation efficiency.

\section{Conclusions}

In summary, the effect of the addition of the nano $\mathrm{MgO}$ particles on the hot compression behavior and processing maps of MZC was examined in the present work. The following brief conclusions can be drawn:

(1) The crystal structure analysis showed that $\mathrm{MgO}$ particles can be used as effective and stable nucleation cores of a Mg matrix, and a fine and more homogeneous microstructure of MZCM was formed with the addition of nano $\mathrm{MgO}$ particles.

(2) The flow stress of MZC and MZCM showed typical DRX features, and the flow stress of MZCM is lower than that of MZC during deformation at $523-623 \mathrm{~K}$ but this result is the opposite at $673 \mathrm{~K}$ and 
$0.1-1 \mathrm{~s}^{-1}$. The average $\varepsilon_{\mathrm{c}} / \varepsilon_{\mathrm{p}}$ value of MZCM is lower than that of MZC, revealing that the addition of nano $\mathrm{MgO}$ promotes the DRX of MZC. This result is consistent with microstructure evolution.

(3) The constitutive equation of MZCM was developed; the $n$ and $m$ value show that dislocation climb is the dominate compressive deformation mechanism for MZC and MZCM, but the higher $m$ value of MZCM might be attributed to the grain boundary sliding mechanism. The $n$ and $Q$ values of MZCM were lower than those of MZC under the same deformation condition, but the $m$ value showed a reverse trend, which implies that the addition of nano $\mathrm{MgO}$ particles decreases the stress sensitivity and deformation resistance for thermal deformation and improves the plasticity of MZC.

(4) According to the processing maps, compared with MZC, MZCM exhibits higher power dissipation efficiency, a larger DRX region and smaller instability regions, but the area of the low-temperature high strain-rate instability region for MZCM is larger and the area of the low-temperature high strain-rate instability region instability region for MZCM is smaller. Combined with microstructure evolution, a relatively lower $Z$ value means sufficient DRX occurred in MZCM, and the optimum hot working condition for MZCM was determined to be $623-653 \mathrm{~K}$ and $0.01-0.001 \mathrm{~s}^{-1}$.

Author Contributions: Conceptualization, M.C.; investigation, L.Y.; writing—original draft preparation, H.Z.; writing-review and editing, H.Z., S.L., C.Y. and M.C.; funding acquisition, M.C. All authors have read and agreed to the published version of the manuscript.

Funding: This research was funded by the National Natural Science Foundation of China, grant numbers U1764254 and 51871166.

Conflicts of Interest: The authors declare no conflict of interest.

\section{References}

1. Ahmad, R.; Wu, Z.X.; Curtin, W.A. Analysis of double cross-slip of pyramidal I $<\mathrm{c}+\mathrm{a}>$ screw dislocations and implications for ductility in Mg alloys. Acta Mater. 2020, 183, 228-241. [CrossRef]

2. Bommal, V.K.; Krishn, M.G.; Rao, C.T. Magnesium matrix composites for biomedical applications: A review. J. Magn. Alloys 2019, 7, 72-79. [CrossRef]

3. Zheng, Y.F.; Gu, X.N.; Xi, Y.L.; Chai, D.L. In vitro degradation and cytotoxicity of Mg/Ca composites produced by powder metallurgy. Acta Biomater. 2010, 6, 1783-1791. [CrossRef] [PubMed]

4. Pollock, T. Weight Loss with Magnesium Alloys. Science 2010, 328, 986-987. [CrossRef] [PubMed]

5. Zheng, H.R.; Li, Z.; You, C.; Chen, M.F. Effects of $\mathrm{MgO}$ modified $\beta$-TCP nanoparticles on the microstructure and properties of $\beta-\mathrm{TCP} / \mathrm{Mg}-\mathrm{Zn}-\mathrm{Zr}$ composites. Bioact. Mater. 2017, 2, 1-9. [CrossRef]

6. Chen, Y.W.; Moussi, J.; Drury, J.L.; Wataha, J.C. Zirconia in Biomedical Applications. Expert Rev. Med. Devices 2016, 13, 945-963. [CrossRef]

7. Mounib, M.; Pavese, M.; Badini, C.; Lefebvre, W.; Dieringa, H. Reactivity and Microstructure of $\mathrm{Al}_{2} \mathrm{O}_{3}$-Reinforced Magnesium-Matrix Composites. Adv. Mater. Sci. Eng. 2014, 2014, 1-6. [CrossRef]

8. Lei, T.; Tang, W.; Cai, S.H.; Feng, F.F.; Li, N.F. On the corrosion behaviour of newly developed biodegradable Mg-based metal matrix composites produced by in situ reaction. Corros. Sci. 2012, 54, 270-277. [CrossRef]

9. Meenashisundaram, G.K.; Seetharaman, S.; Gupta, M. Enhancing overall tensile and compressive response of pure Mg using nano-TiB2 particulates. Mater. Charact. 2014, 94, 178-188. [CrossRef]

10. Goh, C.S.; Gupta, M.; Wei, J.; Lee, L.C. Characterization of High Performance Mg/MgO Nanocomposites. J. Compos. Mater. 2007, 41, 2325-2335. [CrossRef]

11. Lin, G.Y.; Liu, D.D.; Chen, M.F.; You, C.; Li, Z.; Wang, Y. Preparation and characterization of biodegradable $\mathrm{Mg}-\mathrm{Zn}-\mathrm{Ca} / \mathrm{MgO}$ nanocomposites for biomedical applications. Mater. Charact. 2018, 144, 120-130. [CrossRef]

12. Shahin, M.; Munir, K.; Wen, C.; Li, Y. Magnesium matrix nanocomposites for orthopedic applications: A review from mechanical, corrosion, and biological perspectives. Acta Biomater. 2019, 96, 1-19. [CrossRef] [PubMed] 
13. Zheng, H.R.; Li, Z.; Chen, M.F.; You, C.; Liu, D. The effect of nano $\beta$-TCP on hot compression deformation behavior and microstructure evolution of the biomedical Mg-Zn-Zr alloy. Mater. Sci. Eng. A 2018, 715, 205-213. [CrossRef]

14. Xiao, P.; Gao, Y.M.; Xu, F.X.; Yang, S.; Li, Y.; Li, B. Hot deformation behavior of in-situ nanosized TiB 2 particulate reinforced AZ91 Mg matrix composite. J. Alloys Compd. 2019, 798, 1-11. [CrossRef]

15. Raj, R. Development of a Processing Map for Use in Warm-Forming and Hot-Forming Processes. Metall. Trans. A 1981, 12, 1089-1097. [CrossRef]

16. Łyszkowski, R.; Bystrzycki, J. Hot deformation and processing maps of a Fe-Al intermetallic alloy. Mater. Charact. 2014, 96, 196-205. [CrossRef]

17. Zhang, L.; Wang, Q.; Liu, G.; Guo, W.; Jiang, H.; Ding, W. Effect of SiC particles and the particulate size on the hot deformation and processing map of AZ91 magnesium matrix composites. Mater. Sci. Eng. A 2017, 707, 315-324. [CrossRef]

18. Fan, Z.; Zuo, Y.B.; Jiang, B. A new technology for treating liquid metals with intensive melt shearing. Mater. Sci. Forum 2011, 690, 141-144. [CrossRef]

19. Cheng, W.L.; Bai, Y.; Ma, S.C.; Wang, L.; Wang, H.; Yu, H. Hot deformation behavior and workability characteristic of a fine-grained Mg-8Sn-2Zn-2Al alloy with processing map. J. Mater. Sci. Tech. 2019, 35, 1198-1209. [CrossRef]

20. Hao, J.Q.; Zhang, J.S.; Xu, C.X.; Ni, K. Optimum parameters and kinetic analysis for hot working of a solution-treated Mg-Zn-Y-Mn magnesium alloy. J. Alloys Compd. 2018, 754, 283-296. [CrossRef]

21. Chadha, K.; Shahriari, D.; Tremblay, R.; BHATTACHARJEE, P.P.; JAHAZI, M. Deformation and Recrystallization Behavior of the Cast Structure in Large Size, High Strength Steel Ingots: Experimentation and Modeling. Metall. Mater. Trans. A 2017, 48, 4297-4313. [CrossRef]

22. Tahreen, N.; Zhang, D.F.; Pan, F.S.; Jiang, Q.; Li, C.; Li, D.Y. Characterization of hot deformation behavior of an extruded Mg-Zn-Mn-Y alloy containing LPSO phase. J. Alloys Compd. 2015, 644, 814-823. [CrossRef]

23. Prasad, Y.V.R.K.; Seshacharyulu, T. Processing maps for hot working of titanium alloys. Mater. Sci. Eng. A 1998, 243, 82-88. [CrossRef]

24. Ansari, N.; Tran, B.; Poole, W.J.; Singh, S.S.; Krishnaswamy, H.; Jain, J. High temperature deformation behavior of Mg-5wt.\%Y binary alloy: Constitutive analysis and processing maps. Mater. Sci. Eng. A 2020, 777, 139051. [CrossRef]

25. Kwak, T.Y.; Kim, W.J. Effect of refinement of grains and icosahedral phase on hot compressive deformation and processing maps of Mg-Zn-Y magnesium alloys with different volume fractions of icosahedral phase. J. Mater. Sci. Tech. 2019, 35, 181-191. [CrossRef]

26. Suttona, S.C.; Luo, A.A. Constitutive behavior and processing maps of a new wrought magnesium alloy ZE20 (Mg-2Zn-0.2Ce). J. Magn. Alloys 2020, 8, 111-126. [CrossRef]

27. Wang, W.Y.; Tang, B.; Shang, S.L.; Wang, J.; Li, S.; Wang, Y. Local lattice distortion mediated formation of stacking faults in Mg alloys. Acta Mater. 2019, 170, 231-239. [CrossRef]

28. Bramfitt, B.L. The effect of carbide and nitride additions on the heterogeneous nucleation behavior of liquid iron. Metall. Trans. 1970, 1, 1987-1995. [CrossRef]

29. Li, L.; Wang, Y.; Li, H.; Jiang, W.; Wang, T.; Zhang, C.C.; Wang, F.; Garmestani, H. Effect of the Zener-Hollomon parameter on the dynamic recrystallization kinetics of $\mathrm{Mg}-\mathrm{Zn}-\mathrm{Zr}-\mathrm{Yb}$ magnesium alloy. Comp. Mater. Sci. 2019, 166, 221-229. [CrossRef]

30. He, D.G.; Lin, Y.C.; Chen, J.; Chen, D.D.; Huang, J.; Tang, Y. Microstructural evolution and support vector regression model for an aged Ni-based superalloy during two-stage hot forming with stepped strain rates. Mater. Des. 2018, 154, 51-62. [CrossRef]

31. Queen, H.J.; Ryan, N.D. Constitutive analysis in hot working. Mater. Sci. Eng. A 2002, 322, $43-63$.

32. Xia, X.S.; Chen, Q.; Huang, S.H.; Lin, J.; Hu, C.; Zhao, Z. Hot deformation behavior of extruded Mg-Zn-Y-Zr alloy. J. Alloys Compd. 2015, 644, 308-316. [CrossRef]

33. Tahreen, N.; Zhang, D.F.; Pan, F.S.; Jiang, X.Q.; Li, D.Y.; Chen, D.L. Hot deformation and processing map of an as-extruded Mg-Zn-Mn-Y alloy containing I and W phases. Mater. Des. 2015, 87, 245-255. [CrossRef]

34. Xia, X.; Chen, Q.; Zhang, K.; Zhao, Z.; Ma, M.; Li, X. Hot deformation behavior and processing map of coarse-grained Mg-Gd-Y-Nd-Zr alloy. Mater. Sci. Eng. A 2013, 587, 283-290. [CrossRef]

35. Poliak, E.I.; Jonas, J.J. Initiation of Dynamic Recrystallization in Constant Strain Rate Hot Deformation. ISIJ Int. 2003, 43, 684-691. [CrossRef] 
36. Jonas, J.J.; Quelennec, X.; Jiang, L.; Martin, E. The Avrami kinetics of dynamic recrystallization. Acta Mater. 2009, 57, 2748-2756. [CrossRef]

37. Barnett, M.R. Hot Working Microstructure Map for Magnesium AZ31. Mater. Sci. Forum 2003, 426, 515-520. [CrossRef]

38. Park, S.H.; Jung, J.G.; Kim, Y.M.; You, B.S. A new high-strength extruded Mg-8Al-4Sn-2Zn alloy. Mater. Lett. 2015, 139, 35-38. [CrossRef]

39. Sherby, O.D.; Wadsworth, J. Superplasticity-Recent advances and future directions. Prog. Mater. Sci. 1989, 33, 169-221. [CrossRef]

40. Mabuchi, M.; Ameyama, K.; Iwasaki, H.; Higashi, K. Low temperature superplasticity of AZ91 magnesium alloy with non-equilibrium grain boundaries. Acta Mater. 1999, 47, 2047-2057. [CrossRef]

41. Panicker, R.; Chokshi, A.H.; Mishra, R.K.; Verma, R.; Krajewski, P.E. Microstructural evolution and grain boundary sliding in a superplastic magnesium AZ31 alloy. Acta Mater. 2009, 57, 3683-3693. [CrossRef]

42. Tong, L.B.; Zheng, M.Y.; Zhang, D.P.; Gan, W.M.; Brokmeier, H.G.; Meng, J. Compressive deformation behavior of Mg-Zn-Ca alloy at elevated temperature. Mater. Sci. Eng. A 2013, 586, 71-77. [CrossRef]

43. Yue, C.X.; Zhang, L.W.; Liao, S.L.; Pei, J.B.; Gao, H.J.; Jia, Y.W. Research on the dynamic recrystallization behavior of GCr15 steel. Mater. Sci. Eng. A 2009, 499, 177-181. [CrossRef]

(C) 2020 by the authors. Licensee MDPI, Basel, Switzerland. This article is an open access article distributed under the terms and conditions of the Creative Commons Attribution (CC BY) license (http://creativecommons.org/licenses/by/4.0/). 